\title{
On the Effectiveness of Emotion Regulation Training in Anger Management and Emotional Regulation Difficulties in Adolescents
}

\author{
Saadi Lotfali ${ }^{1}$, Alireza Moradi ${ }^{2} \&$ Hamed Ekhtiari $^{3}$ \\ ${ }^{1}$ Cognitive psychologist (MA), Institute for cognitive science studies, Tehran, Iran\& School Consultant, \\ Education District 2 of Karaj, Iran \\ ${ }^{2}$ Professor in clinical psychology(Ph.D), Kharazmi University, Tehran, Iran \& Institute for Cognitive Science \\ Studies, Tehran, Iran \\ ${ }^{3}$ Faculty Member and Director of Translational Neuroscience Program (MD), Institute for cognitive science \\ studies, Tehran, Iran
}

Correspondence: Saadi Lotfali, Cognitive psychologist (MA), Institute for cognitive science studies, Tehran, Iran\& School Consultant, Education District 2 of Karaj, Iran. E-mail: Saadi_lotfali@yahoo.com

Received: September 27, 2016

Accepted: October 6, 2016

Online Published: October 17, 2016

doi:10.5539/mas.v11n1p114

URL: http://dx.doi.org/10.5539/mas.v11n1p114

\begin{abstract}
Introduction: Considering the high prevalence of anger problems in adolescence and the importance of emotion regulation in this age period, this study aims to assess the effectiveness of emotional regulation training in anger management and emotion regulation difficulties in adolescents by means of body postures, breathing pattern, and facial expressions.

Method: A quasi-experimental research design along with pretest-posttest and control group was employed for the conduct of this study. For this purpose, the number of 50 adolescents was selected via purposive sampling through screening based on inclusion and exclusion criteria. These participants were randomly assigned to experimental and control groups and the experimental group then received 8 sessions of emotion regulation training. In this period, the control group received the treatment unrelated to emotion regulation training. Both groups were assessed in terms of Difficulties in Emotion Regulation Scale (DERS) and State-Trait Anger Expression Inventory-2 (STAXI-2) before and after the treatment as well as in the three-month follow-up. The collected data were analyzed by descriptive and inferential statistics, including covariance analysis.
\end{abstract}

Results: Data analysis showed that emotion regulation training has a significant effect on anger management and components emotion regulation difficulties in adolescents.

Conclusion: As per the results of this study, it is recommended that emotion regulation training be extensively conducted in the form of educational and training programs for adolescents, especially in schools.

Keywords: emotional regulation, anger management, emotion regulation difficulties, adolescents

\section{Introduction}

Increased violence among adolescents in recent decades has greatly received the attention of researchers and therapists in the fields related to this issue. Anger is classified in two categories, i.e. verbal and physical. Although anger is a natural emotion, its inappropriate expression poses several problems and has led to the incidence of the concern and attention of parents, teachers, and the public health community (Campano \& Munakata, 2004; Neighbors, Vietor \& Knee, 2002; Bushman \& Anderson, 2002). If anger is not managed and controlled, the sufferers will encounter aggression. Anger and its expression are among the major problems in school children and adolescents (Blake \& Hamrin, 2007). Anger in adolescence can bring about irreversible consequences such as murder (Fives \& Fuller, 2011). Anger has been defined as a destructive and negative emotion that is intensely variable and causes many problems for individuals and their friends (McCarthy, Barnes \& Alpert, 1998). In addition, anger is associated with physiological changes, cognitive distortions, and negative emotions (Kassinove \& Sukholdosky, 1995). The problems associated with anger constitute the most common cause of children and adolescents' reference for psychological services (Abikoff \& Klein, 1992). Anger results in catastrophic consequences, such as coronary heart disease and addiction in adolescents (Barbour, et al., 1998). Anger is one of the emotions that is created when faced with obstacles in the way of goals and becomes some 
motivation for reaching different solutions, which are sometimes accompanied by negative implications (Dennis, et al., 2009) As an emotion, anger is associated with emotional dysregulation and difficulty (Blel, et al., 2004). Emotion regulation is one of the factors causing and perpetuating psychological problems (Aldao \& Nolen-Hoeksema, 2010). The role of emotion regulation in psychiatric disorders has been proved and dysfunction or difficulty in emotional regulation can be associated with several disorders (Lafrance, et al., 2014). Emotion regulation refers to the capacity to monitor, assess, understand, and modify the emotional reactions with appropriate functioning (Gross \& Thompson, 2007). Psychological adaptation and compliance depend largely on emotion regulation, most psychological disorders are marked by emotional disorders, and these disorders are substantially related to dysfunction in emotion regulation. In human life, the experience of negative emotions is inevitable and there is undoubtedly considerable potential for the incidence of emotion regulation difficulties in everyday life. Emotion regulation difficulties can be one of the factors underlying psychological problems (Berking \& Wupperman, 2012). Emotional dysregulation is correlated with anger; for example, the individuals who use maladaptive emotion regulation strategies, such as suppression have been proved to use high levels of anger in comparison with those who use adaptive re-appraisal strategies (Szasz et al., 2011).

Emotion regulation is one of the methods that can be used in relation to the variables mentioned above. Alba Emoting is also one of the methods that refers to the voluntary production and change of emotions change and is composed of three components, namely breathing patterns, body postures, and facial expressions (Kalawski, 2011).

By means of Alba emoting, educators will become able to help their students and apprentices better identify their emotions, as well as identify, become aware of, and regulate their emotions more appropriately. Several studies have supported the significance of the role of physical components in emotions and their regulation. James (1884) was the first researcher who emphasized the role of organism, face, and body posture in emotions. However, considering facial expressions from the body may not be correct. Facial expressions are considered as some part of body posture. For example, the selection of a particular facial expression may affect judgment and emotional memories. Similarly, any changes in body posture and position can affect behavior. Sunken mode can create the majority of desperation behaviors (Kalawski, 2015).

Among the three mentioned components, studies show that body posture is more effective in the creation and induction of emotion. Evidence suggests that body movement can influence emotional states. In the same way, deep signs of facial feedback can be effective in the quality and intensity of emotions (Duncan \& Laird, 1980).

Given the high prevalence of anger among adolescents and its association with emotional regulation difficulties as well as the negative consequences of this phenomenon in this age, it can be raised as a problematic issue in a variety of environments, such as families, schools, and public environments. Accordingly, this study aims to train anger regulation to students and evaluate its effectiveness by means of Alba emoting, which consists of facial expressions, body posture, and breathing pattern.

\section{Method}

The present study was conducted in the form of a quasi-experimental research design along with pretest-posttest and control group. All students Ali ebn Abi Talib school of Karaj (Iran) in 2014 constituted the statistical population of this study. Among this population, the number of 50 adolescent was selected as the sample via purposive sampling through screening by STAXI-2 (State-Trait Anger Expression Inventory-2). It is noteworthy that the inclusion criteria encompassed no use of psychiatric drugs, no history of physical illness, no educational failure and sensible educational relegation, and informed consent on participating in the study. Thereafter, these participants were randomly assigned to experimental and control groups and received eight 90 -minute training sessions of emotional regulation package. During this period, the control group received the treatment irrelevant to emotion regulation training, i.e. the introduction of academic disciplines. Both groups were assessed in terms of Difficulties in Emotion Regulation Scale (DERS) and STAXI-2 (State-Trait Anger Expression Inventory-2) before and after the treatment as well as in the three-month follow-up stage. Then, the collected data were analyzed by descriptive and inferential statistics, including covariance analysis.

Spielberger's State-Trait Anger Expression Inventory (1988): In this study, the Persian version of this questionnaire, referred to as STAXI-2, was used. This test consists of three parts and 57 items. These three parts include state anger, trait anger, and expression and control methods of anger. The State Anger scale assesses the intensity of anger as an emotional state at a particular time; it includes three subscales (State Anger/ Feeling, State Anger/ Verbal, State Anger/ Physical which assess Anger Feelings and Expression of Verbal and Physical Anger). The Trait Anger scale measures how often angry feelings are experienced over time; it includes two subscales. The Anger Expression and Anger Control scales assess four relatively independent anger-related traits: 
expression of angry feelings toward other persons or objects in the environment (Anger Expression-Out), holding in or suppressing angry feelings (Anger Expression-In), controlling angry feelings by preventing the expression of anger toward other persons or objects in the environment (Anger Control-Out), and controlling suppressed angry feelings by calming down or cooling off (Anger Control-In). Each of the items is scored using a four-degree Likert scale. However, items of the first part (state anger) are rated using one of the four modes, namely never, slightly, moderately, very much; and the second and third parts are scored using one of four modes, namely almost never, sometimes, often, and almost always. It takes about 12 to 15 minutes to complete the questionnaire. Cronbach's alpha coefficients of the questionnaire sub-scales in the present study were obtained in the range of .71 to .79 .

Difficulties in Emotion Regulation Scale (DERS): This is a 36-item scale, which was developed by Gratz \& Roemer (2004). It has a total score and 6 specific scores below pertaining to different dimensions of emotional regulation difficulties. These sub-scales include non-acceptance of emotional responses (non-accept), difficulties engaging in goal directed behavior(goals), impulse control difficulties(impulse), lack of emotional awareness(aware), limited access to emotion regulation strategies(strategies), and lack of emotional clarity(clarity). The items are scored based on a 5-point Likert scale. This scale takes advantage of desired reliability and validity (Gratz \& Roemer, 2004). Cronbach's alpha coefficients of the questionnaire sub-scales in this study were obtained in the range of .69 to .82 .

Table 1 presents emotion regulation protocol for the current study in 7 sessions. This protocol has been prepared through the review of previous research and has been set in consultation with experts. Before the start of training, some exercisers were practiced with a target group (other than the study group) and the required modifications were applied.

Table 1. The emotion regulation training protocol in this study

\begin{tabular}{|c|c|}
\hline Training sessions & Content and the number of exercises \\
\hline First session & $\begin{array}{l}\text { The members' acquaintance with each other, explanation about the training and session } \\
\text { process, some training techniques about emotion. }\end{array}$ \\
\hline Second session & $\begin{array}{l}\text { Exercise of producing anger emotion and neutral emotion in sitting mode, including } \\
\text { four exercises for each emotion, namely: emotion production using each of the } \\
\text { components of facial expression, body posture, and breathing pattern alone, * and } \\
\text { emotion production using all the three components at the same time. }{ }^{* *}\end{array}$ \\
\hline Third session & $\begin{array}{l}\text { Practice of producing anger emotion and neutral emotion in sitting and standing } \\
\text { modes, including four exercises, namely: neutral emotion in sitting and standing } \\
\text { modes, anger emotion in sitting and standing modes. }\end{array}$ \\
\hline Fourth session & $\begin{array}{l}\text { Practice of producing anger emotion and neutral emotion in sitting and standing } \\
\text { modes, including four exercises, namely: neutral emotion in sitting and standing } \\
\text { modes, anger emotion in sitting and standing modes (the same as the third session). }\end{array}$ \\
\hline Fifth session & $\begin{array}{l}\text { Continuous and consecutive practice of both the complete state of anger emotion and } \\
\text { neutral emotion in sitting mode (three consecutive training exercises are practiced: a: } \\
\text { neutral emotion, b: anger emotion, and c: neutral emotion once more).*** }\end{array}$ \\
\hline Sixth session & $\begin{array}{l}\text { Continuous and consecutive practice of both the complete state of anger emotion and } \\
\text { neutral emotion in sitting and standing modes (three consecutive training exercises are } \\
\text { practiced) }\end{array}$ \\
\hline Seventh session & $\begin{array}{l}\text { This follow-up session included a review of the previous trainings and doing some } \\
\text { exercises to strengthen the learned items and to tackle the participants' problems and } \\
\text { questions. }\end{array}$ \\
\hline
\end{tabular}

*To produce each emotion, the participants create the required states in themselves for five minutes; for example, they create the practice of body posture pertaining to the emotional state of anger and stay for five minutes in that state so that the anger emotion can be produced. They pay attention to the resultant biological and cognitive changes. Following the five minutes, they stabilize their bodily cognitive status in order to create emotional awareness and then they will report and read it for the other group members. (This practice is an attempt to produce emotion and increase emotional awareness). 
** Producing anger emotion or neutral emotion by the simultaneous use of the three components of body posture, facial expressions, and breathing pattern, the participants first perform the body posture pertaining to anger state. Thereafter, they remain one minute in this mode and add the state of facial expressions to it. After one minute, they add the breathing pattern of anger to the two states (, i.e. body posture and facial expressions) and continue their exercise for three minutes. The record and report of the biological and cognitive status will be finally performed. (This practice is to learn how to create emotion and increase emotional awareness).

*** In this practice, the participants make changes into in all the three components, including body posture, facial expressions, and breathing pattern at the same time. In other words, they are required to make necessary changes into their body postures, facial expressions, and breathing patterns in order to produce anger emotion. They then make necessary changes into the three components at the time of the transition of anger emotion to neutral emotion. In this practice, both anger and neutral emotions are exercised from two to three minutes and the anger emotion is exercised for two to three minutes again. (This practice is to learn how to create emotion and change it).

\section{The preparation method of Emotion Regulation Training Package}

This technique is based on a method referred to as Alba emoting that is rooted in the research areas concentrating on physiological components (breathing pattern, facial expressions, and body postures) in the production and regulation of emotions. In 1970, Susana Bloch \& Guy Santibanez studied physiological changes during the period of experiencing various emotions. They recorded these changes with the production of emotions and normal emotional states. Finally, they presented a model called Alba emoting by using spirometer to accurately record breathing patterns, facial expressions, and body postures. By means of this method, people can possibly create the preferred emotion in themselves and change it to any desired without any intrinsic or extrinsic stimuli. This technique was developed for artists and movie actors to create the required emotions in playing their role (Kalawski,2011). Since there was no training Alba emoting centers available to the researcher and there was no video footage of this method, the researcher prepared the initial training package by modeling Alba emoting method. Then, the method was experimented in a 5-people group as a pilot study and the techniques of the final package were modified under the guidance of university supervisors and advisors. In this way, the finalized techniques were obtained. The possibility of production of anger and its conversion into a neutral emotional state and vice versa was created using the final package techniques, which met the researcher's wishes. The final training package of anger emotion regulation was trained to the original research group (experimental group) in accordance with the protocol and its effectiveness was evaluated. In Table 2, the training package techniques of anger emotion regulation are presented.

Table 2. Emotion regulation techniques in the current study

\begin{tabular}{|c|c|}
\hline Anger mode & Neutral mode \\
\hline $\begin{array}{l}\text { Body posture: } \\
\text { Slight inclination of the body to the forward direction, partial pressure } \\
\text { of feet on the ground, and creation of a bit of pressure on the muscles of } \\
\text { the legs are evident. Slight contraction of abdominal, chest, and neck } \\
\text { muscles, the forward direction of chest, and stretching of shoulder } \\
\text { muscles. The fisted state of hands on either side in standing mode and } \\
\text { on knees in sitting mode, and its slight pressure on knees } \\
\text { Note: (No severe muscle pressure and contraction, that is, they should } \\
\text { not cause cramps in the muscles). }\end{array}$ & $\begin{array}{l}\text { Body posture: } \\
\text { Body relaxation (shoulder-width } \\
\text { opening of the feet in the same } \\
\text { direction, no contraction of foot } \\
\text { muscles, smooth waist, fallen } \\
\text { shoulders, and open arms in both } \\
\text { sides). No contraction and stretch in } \\
\text { any of the muscles. }\end{array}$ \\
\hline $\begin{array}{l}\text { Facial expressions: } \\
\text { The muscles wrinkling the eyebrows are lowered and drawn inside } \\
\text { (frown). The mouth is closed, upper and lower teeth cover each other, } \\
\text { lip muscles are spiral, and the lips are tightly squeezed. } \\
\text { Eyes become narrow and fixed at a specific location. Note: Focus } \\
\text { should not be placed on a specific point. }\end{array}$ & $\begin{array}{l}\text { Facial expressions: } \\
\text { All the facial muscles are relaxed and } \\
\text { flaccid (especially the forehead is not } \\
\text { wrinkled). Eyes are on the horizon and } \\
\text { no focus is on a specific point. The } \\
\text { mouth is partially open. }\end{array}$ \\
\hline $\begin{array}{l}\text { Breathing pattern: } \\
\text { Fast inhale and exhale through the nose } \\
\text { Note: The depth of breathing should not be too short (because it gives } \\
\text { the feeling of weakness). }\end{array}$ & $\begin{array}{l}\text { Breathing pattern: } \\
\text { The same speed of inhale and exhale, } \\
\text { slow and almost deep breathing } \\
\text { Inhale through the nose and exhale } \\
\text { through the mouth. }\end{array}$ \\
\hline
\end{tabular}




\section{Results}

The mean values of participants' age in the experimental group and the control group equal 16.83 and 16.25 years, respectively. Independent two-tailed T test was used to examine the whether both groups are matched in terms of age. The results $(\mathrm{P}>.05)$ showed that the age distribution does not show a significant difference between the two groups. In other words, the groups were matched based on this variable.

Analysis of covariance was used to analyze the data. Before the start of the analysis, normality of data distribution and homogeneity of variance in both groups were checked to ensure the satisfaction of covariance analysis assumptions.

Table 3. shows the descriptive statistics of anger in the experimental and control groups in pre-test, post-test, and follow-up.

Table 3. Descriptive statistics of anger management dimensions of the experimental and control groups based on the evaluation stages

\begin{tabular}{llllll}
\hline Emotional dimensions & Group & N & $\begin{array}{l}\text { Pre-test } \\
(S D) \text { Mean }\end{array}$ & $\begin{array}{l}\text { Post-test } \\
(\text { SD) Mean }\end{array}$ & $\begin{array}{l}\text { Follow-up } \\
\text { (SD) Mean }\end{array}$ \\
\hline State Anger/ Feeling & Experimental & $\mathbf{2 5}$ & $12.12(3.34)$ & $9.76(2.06)$ & $10.53(3.46)$ \\
& Control & $\mathbf{2 5}$ & $11.84(3.84)$ & $12.27(4.24)$ & $12.07(4.17)$ \\
State Anger/ Verbal & Experimental & $\mathbf{2 5}$ & $10.64(3.54)$ & $8.65(4.26)$ & $9.12(3.62)$ \\
& Control & $\mathbf{2 5}$ & $10.44(3.23)$ & $11.07(1.99)$ & $10.37(3.82)$ \\
State Anger/ Physical & Experimental & $\mathbf{2 5}$ & $12.40(4.64)$ & $9.72(4.26)$ & $10.22(4.33)$ \\
& Control & $\mathbf{2 5}$ & $12.33(3.98)$ & $12.56(4.04)$ & $12.17(4.35)$ \\
Trait Anger/ Temperament & Experimental & $\mathbf{2 5}$ & $8.38(2.81)$ & $7.64(2.36)$ & $8.12(2.46)$ \\
& Control & $\mathbf{2 5}$ & $8.56(2.43)$ & $8.60(2.54)$ & $9.21(3.17)$ \\
Trait Anger/ Reaction & Experimental & $\mathbf{2 5}$ & $\mathbf{1 6 / 9 6 ( 3 / 8 6 )}$ & $15.36(3.46)$ & $15.82(3.77)$ \\
& Control & $\mathbf{2 5}$ & $17.04(2.78)$ & $16.80(3.58)$ & $17.21(3.18)$ \\
Anger Expression- Out & Experimental & $\mathbf{2 5}$ & $16.84(7.74)$ & $18.88(4.24)$ & $18.29(4.35)$ \\
& Control & $\mathbf{2 5}$ & $17.04(4.42)$ & $17.12(4.15)$ & $16.97(4.46)$ \\
Anger Expression- In & Experimental & $\mathbf{2 5}$ & $23.40(3.50)$ & $21.44(2.77)$ & $22.13(3.41)$ \\
& Control & $\mathbf{2 5}$ & $23.20(3.30)$ & $23.12(2.94)$ & $23.57(3.48)$ \\
Anger Control- Out & Experimental & $\mathbf{2 5}$ & $18.84(4.18)$ & $20.96(5.25)$ & $19.12(4.63)$ \\
& Control & $\mathbf{2 5}$ & $18.96(3.83)$ & $19.12(3.41)$ & $18.74(3.59)$ \\
Anger Control- In & Experimental & $\mathbf{2 5}$ & $22.00(4.07)$ & $20.08(5.10)$ & $20.42(3.83)$ \\
& Control & $\mathbf{2 5}$ & $22.12(3.58)$ & $21.40(3.58)$ & $21.72(4.14)$ \\
\hline
\end{tabular}

According to Table 3, marked changes can be observed in the post-test and follow-up scores of the experimental group in terms of such sub-scales as State Anger/ Feeling, State Anger/ Verbal, State Anger/ Physical, Trait Anger/ Temperament, Trait Anger/ Reaction, Anger Expression- Out, Anger Expression- In, Anger Control- Out, Anger Control- In. However, these changes were not significant in the control group. In the following, analysis of covariance was used to evaluate the significance of the impact of emotion regulation training on anger management. Kolmogorov-Smirnov test results ranged from .062 to .114, which represented the normal distribution of the data and Leven's test scores ranged from .086 to .164, denoted the homogeneity of variance in the two groups. Thus, these assumptions have been met. Table 3 shows the results of analysis of covariance on the investigation of the effectiveness of emotional regulation training in anger management among senior high school students based on group membership in the post-test. 
Table 4. Covariance analysis results for the verification of the effectiveness of emotion regulation training in anger management dimensions among senior high school students in the post-test based on group membership

\begin{tabular}{lllllll}
\hline $\begin{array}{l}\text { Dimensions of } \\
\text { Management }\end{array}$ & Anger Group & df & $\begin{array}{l}\text { Mean } \\
\text { Square }\end{array}$ & F ratio & Sig. & $\begin{array}{l}\text { Effect } \\
\text { size }\end{array}$ \\
\hline State Anger/ Feeling & Pre-test & 15 & 48.318 & 5.472 & .084 & .273 \\
& Group membership & $\mathbf{1 5}$ & 65.720 & $\mathbf{1 0 . 7 4 2}$ & .001 & .464 \\
State Anger/ Verbal & Pre-test & $\mathbf{1 5}$ & 52.617 & 8.306 & .014 & .361 \\
& Group membership & $\mathbf{1 5}$ & 74.845 & 12.583 & .001 & .586 \\
State Anger/ Physical & Pre-test & $\mathbf{1 5}$ & 23.648 & 3.373 & .116 & .149 \\
& Group membership & $\mathbf{1 5}$ & 88.466 & $\mathbf{1 5 . 6 5 3}$ & .014 & .644 \\
Trait Anger/ Temperament & Pre-test & $\mathbf{1 5}$ & 32.682 & 5.277 & .098 & .169 \\
& Group membership & $\mathbf{1 5}$ & 4.584 & .630 & .417 & .054 \\
Trait Anger/ Reaction & Pre-test & $\mathbf{1 5}$ & 21.580 & 3.363 & .144 & .112 \\
& Group membership & $\mathbf{1 5}$ & 6.467 & .729 & .325 & .067 \\
Anger Expression- Out & Pre-test & $\mathbf{1 5}$ & 57.346 & 11.762 & .004 & .402 \\
& Group membership & $\mathbf{1 5}$ & 80.249 & 14.783 & .001 & .611 \\
Anger Expression- In & Pre-test & $\mathbf{1 5}$ & 30.268 & 4.876 & .107 & .141 \\
& Group membership & $\mathbf{1 5}$ & 5.843 & .719 & .382 & .063 \\
Anger Control- Out & Pre-test & $\mathbf{1 5}$ & 47.275 & 4.862 & .007 & .263 \\
& Group membership & $\mathbf{1 5}$ & 83.249 & 15.044 & .001 & .621 \\
Anger Control- In & Pre-test & $\mathbf{1 5}$ & 28.544 & 4.277 & .137 & .139 \\
& Group membership & $\mathbf{1 5}$ & 6.584 & .922 & .343 & .075 \\
\hline
\end{tabular}

According to the results of covariance analysis, it is observed in Table 3 that the experimental group's post-test scores have undergone more tangible changes than the control group's scores in such sub-scales as State Anger/ Feeling, State Anger/ Verbal, State Anger/ Physical, Anger Expression- Out, and Anger Control- Out $(\mathrm{P}<.05)$. The calculated effect sizes show that emotion regulation training has led to a 46-percent reduction in anger feelings, a 59-percent reduction in State Anger/ Verbal, a 64-percent reduction in State Anger/ Physical, a 61-percent reduction in Anger Expression- In, and a 62-percent reduction in Anger Expression- Out. In other subscales, the observed differences were not statistically significant. Table 5 shows the results of analysis of covariance representing the assessment of the impact of emotional regulation training on anger management among senior high school students in the follow-up phase based on group membership.

Table 5. Covariance analysis results for the verification of the effectiveness of emotion regulation training in anger management dimensions among senior high school students in the follow-up phase based on group membership

\begin{tabular}{llllll}
\hline Dimensions of Anger Management & Group & df & Mean Square & F ratio & Sig. \\
\hline \multirow{2}{*}{ State Anger/ Feeling } & Pre-test & 31.164 & 5.272 & .096 & .152 \\
& Group membership & 27.249 & 4.258 & .137 & .141 \\
State Anger/ Verbal & Pre-test & 19.744 & 2.537 & .107 & .086 \\
& Group membership & 54.572 & 9.838 & .011 & .374 \\
State Anger/ Physical & Pre-test & 26.471 & 3.974 & .125 & .133 \\
& Group membership & 61.466 & 13.470 & .001 & .438 \\
Trait Anger/ Temperament & Pre-test & 12.479 & 1.277 & .273 & .036 \\
& Group membership & .438 & .352 & .835 & .014 \\
Trait Anger/ Reaction & Pre-test & 14.547 & 1.738 & .215 & .041 \\
& Group membership & .389 & .254 & .862 & .011 \\
Anger Expression- Out & Pre-test & 23.627 & 4.386 & .144 & .118 \\
& Group membership & 38.269 & 7.405 & .068 & .194 \\
Anger Expression- In & Pre-test & 9.593 & .979 & .483 & .021 \\
& Group membership & .372 & .259 & .740 & .003 \\
Anger Control- Out & Pre-test & 16.728 & 1.942 & .269 & .052 \\
& Group membership & 33.671 & 6.163 & .082 & .137 \\
Anger Control- In & Pre-test & 8.639 & .740 & .539 & .018 \\
& Group membership & .453 & .388 & .629 & .008 \\
\hline
\end{tabular}


According to the results of covariance analysis in Table 4, it is observed that the experimental group's follow-up scores have undergone more significant changes than the control group's scores in such sub-scales as State Anger/ Verbal and State Anger/ Physical $(\mathrm{P}<.05)$. The calculated effect sizes show that emotion regulation training has led to a 37-percent reduction in State Anger/ Verbal and a 44-percent reduction in State Anger/ Physical and a 61-percent reduction in Anger Expression- In. In other subscales, the observed differences were not statistically significant.

Table 6 shows the descriptive statistics related to the dimensions of Difficulties in Emotion Regulation Scale for the experimental and control groups in terms of the pre-test, post-test, and follow-up stages.

Table 6. Descriptive statistics of difficulties in emotion regulation in experimental and control groups based on the evaluation stages

\begin{tabular}{llllll}
\hline Emotional dimensions & Group & N & $\begin{array}{l}\text { Pre-test } \\
(\text { SD) Mean }\end{array}$ & $\begin{array}{l}\text { Post-test } \\
(\text { SD) Mean }\end{array}$ & $\begin{array}{l}\text { Follow-up } \\
\text { (SD) Mean }\end{array}$ \\
\hline Non-acceptance & Experimental & $\mathbf{2 5}$ & $15.32(5.64)$ & $13.8(4.84)$ & $14.78(5.13)$ \\
& Control & $\mathbf{2 5}$ & $15.76(4.47)$ & $15.52(3.67)$ & $15.72(3.74)$ \\
Goals & Experimental & $\mathbf{2 5}$ & $15.96(5.98)$ & $12.08(4.16)$ & $14.15(4.52)$ \\
& Control & $\mathbf{2 5}$ & $15.64(3.78)$ & $15.52(3.68)$ & $15.36(3.83)$ \\
Impulse & Experimental & $\mathbf{2 5}$ & $17.60(5.80)$ & $14.68(5.52)$ & $16.18(5.33)$ \\
& Control & $\mathbf{2 5}$ & $17.28(3.47)$ & $17.60(3.20)$ & $17.86(4.25)$ \\
Aware & Experimental & $\mathbf{2 5}$ & $13.24(3.20)$ & $14.64(3.03)$ & $14.32(3.54)$ \\
& Control & $\mathbf{2 5}$ & $13.08(3.16)$ & $12.92(2.62)$ & $12.88(3.45)$ \\
Strategies & Experimental & $\mathbf{2 5}$ & $22.60(7.16)$ & $19.96(3.61)$ & $21.37(3.68)$ \\
& Control & $\mathbf{2 5}$ & $21.76(6.35)$ & $21.60(6.40)$ & $21.39(5.94)$ \\
Clarity & Experimental & $\mathbf{2 5}$ & $13.40(2.38)$ & $14.44(4.35)$ & $13.78(4.44)$ \\
& Control & $\mathbf{2 5}$ & $14.80(2.72)$ & $14.96(2.59)$ & $14.75(3.14)$ \\
\hline
\end{tabular}

According to Table 5, it can be seen that the experimental group has experienced significant changes in the post-test and follow-up stages in terms of non-acceptance, goals, impulse, and strategies. However, these changes are not significant for the control group. Thereafter, analysis of covariance was used to investigate the effect of emotional regulation training on emotional regulation difficulty. Kolmogorov-Smirnov test values ranged from .78 to .652 and Leven's test values range from .124 to .895 , which represent the normality of data distribution and the homogeneity of variances, respectively.

Table 7 presents the covariance analysis results evaluating the effectiveness of emotion regulation training in emotional regulation difficulties among senior high school students in the follow-up stage based on group membership.

Table 7. Covariance analysis results evaluating the effectiveness of emotion regulation training in emotional regulation difficulties among senior high school students in the post-test stage based on group membership

\begin{tabular}{|c|c|c|c|c|c|c|}
\hline Emotional dimensions & Group & $\mathrm{df}$ & $\begin{array}{l}\text { Mean } \\
\text { Square }\end{array}$ & F ratio & Sig. & $\begin{array}{l}\text { Effect } \\
\text { size }\end{array}$ \\
\hline \multirow{2}{*}{ Non-acceptance } & Pre-test & 1 & 30.472 & 7.536 & .004 & .343 \\
\hline & Group membership & 1 & 103.467 & 31.562 & .001 & .742 \\
\hline \multirow{2}{*}{ Goals } & Pre-test & 1 & 27.705 & 6.468 & .001 & .318 \\
\hline & Group membership & 1 & 111.630 & 34.169 & .001 & .774 \\
\hline \multirow{2}{*}{ Impulse } & Pre-test & 1 & 49.758 & 14.377 & .001 & .432 \\
\hline & Group membership & 1 & 96.832 & 28.719 & .001 & .685 \\
\hline \multirow{2}{*}{ Aware } & Pre-test & 1 & 35.238 & 9.741 & .001 & .836 \\
\hline & Group membership & 1 & 7.854 & 1.726 & .213 & .157 \\
\hline \multirow{2}{*}{ Strategies } & Pre-test & 1 & 24.266 & 5.368 & .004 & .283 \\
\hline & Group membership & 1 & 122.634 & 34.257 & .001 & .821 \\
\hline \multirow{2}{*}{ Clarity } & Pre-test & 1 & 26.815 & 6.249 & .001 & .302 \\
\hline & Group membership & 1 & 8.540 & 2.034 & .173 & .186 \\
\hline
\end{tabular}


According to the results of covariance analysis, it can be seen in Table 6 that the mean score of the experimental group has experienced significant changes in terms of non-acceptance, goals, impulse, and strategies compared to the control group $(\mathrm{P}<0.001)$. The calculated effect sizes indicate that emotion regulation training brings about a 74-percent reduction in non-acceptance, a 77-percent reduction in goals, a 68-percent reduction in impulse, and an 82-percent reduction in strategies. In other subscales, the observed differences were not statistically significant.

Table 8 shows the covariance analysis results representing the assessment of the effectiveness of emotion regulation training in emotional regulation difficulties among high school students in the follow-up stage based on group membership.

Table 8. Covariance analysis results representing the effectiveness of emotion regulation training in emotional regulation difficulties among senior high school students in the follow-up stage based on group membership

\begin{tabular}{lllllll}
\hline Emotional dimensions & Group & df & $\begin{array}{l}\text { Mean } \\
\text { Square }\end{array}$ & F ratio & Sig. & $\begin{array}{l}\text { Effect } \\
\text { size }\end{array}$ \\
\hline Non-acceptance & Pre-test & $\mathbf{1 5}$ & 36.548 & 10.637 & .001 & .402 \\
& Group membership & $\mathbf{1 5}$ & 56.372 & 17.274 & .001 & .514 \\
Goals & Pre-test & $\mathbf{1 5}$ & 41.538 & 13.738 & .001 & .473 \\
& Group membership & $\mathbf{1 5}$ & 32.634 & 9.549 & .001 & .368 \\
Impulse & Pre-test & $\mathbf{1 5}$ & 29.753 & 6.377 & .001 & .312 \\
& Group membership & $\mathbf{1 5}$ & 14.832 & 2.719 & .001 & .137 \\
Aware & Pre-test & $\mathbf{1 5}$ & 24.238 & 4.741 & .001 & .265 \\
& Group membership & $\mathbf{1 5}$ & 5.854 & .726 & .001 & .087 \\
Strategies & Pre-test & $\mathbf{1 5}$ & 27.873 & 6.063 & .001 & .283 \\
& Group membership & $\mathbf{1 5}$ & 40.732 & 13.138 & .001 & .456 \\
Clarity & Pre-test & $\mathbf{1 5}$ & 30.563 & 7.404 & .001 & .336 \\
& Group membership & $\mathbf{1 5}$ & 6.418 & 1.893 & .274 & .118 \\
\hline
\end{tabular}

As per the results of covariance analysis in Table 7, it can be observed that the mean score of non-acceptance, goals, impulse, and strategies has significantly changed in the follow-up stage compared to the control group $(\mathrm{P}<.001)$. The calculated effect sizes indicate that emotion regulation training has occasioned a 51-percent reduction in non-acceptance, a 37-percent reduction in goals, a 14-percent reduction in impulse, and a 46-percent reduction in strategies. In other subscales, the observed differences were not statistically significant.

\section{Discussion and Conclusion}

The results of this study showed that the training of emotion regulation package is associated with a significant reduction in the sub-scales of State-Trait Anger Expression Inventory-2 (STAXI-2) and Difficulties in Emotion Regulation Scale (DERS). Anger, impulsive behaviors, shame, and feeling of guilt are among the consequences of ineffective regulation excitement (Sandler, et al., 1994). In fact, anger has been even considered as an emotion that can lead to aggressive behavior (Eisenberg, 2001). In adolescence, anger can be one of the antecedents of risky behavior because of the certain psychological circumstances adolescents are involved in during this period. In addition, anger may result in various high-risk decisions, including smoking and drug use (Gambetti \& Giusberti, 2009). Today, an increase in anger and behaviors resulting from this emotion are prevalently seen in adolescents. Anger can occur in the form of verbal and physical expressions where the expression of verbal anger is represented by shouting, arguing, swearing, etc. However, the expression of physical anger is reflected in assault, beating, grapple, hitting people or tools, and throwing or breaking equipment and appliances. This phenomenon has become a major problem in adolescents that has endangered family health, educational environments, and the society (Feindler \& Engel, 2011).

Emotion regulation training by physiological components helps students reduce their anger and eliminate aggressive behavior. These exercises are associated with reduced sympathetic activity and increased parasympathetic activity, which can severely affect the severity of anger reactions and aggression in adolescents 
(Diamond \& Crete, 2013). In addition, these exercises lead to the improvement of emotion regulation through changes in the activity of brain structures. For example, the activity of the prefrontal cortex increases. This area is responsible for the executive functions. The proper functioning of these abilities can be effective in a variety of everyday decisions and eventually leads to more effective emotion regulation (Tang, et al., 2015). Functional changes in the prefrontal cortex and limbic lobes arising from these interventions can contribute to the better inhibition and greater emotion regulation. The frontal cortex activity can not only be effective in emotion regulation but also be effective in our daily operations (Muir, et al., 2011). According to the participants' report, an opportunity was provided for them to explore their problems from different perspectives and obtain a solution other than aggression for their problems. Therefore, they show a more goal-directed manner than before. The components of the research training package are directly effective in emotional awareness of adolescents. Emotional awareness and selective attention process lead people to have an accurate assessment of their feelings and the situation in which they are placed (Rommel, et al., 2012). Lack of emotional awareness in adolescents can lead to the inability in the identification of their own emotions as well as the others' emotions. This can interfere in their social judgment and associate them with inappropriate responses in social situations. This lack of emotional aware ness is correlated with anxiety and depression symptoms (Aricak \& Ozbay, 2016). All the above-mentioned items can accelerate the incidence of high-risk behaviors and trigger problematic and destructive behaviors such as aggression in adolescence (Kurniawan \& Dewi, 2016). The present treatment may lead to emotional awareness when it is followed by the training of physiological changes, such as increased heart rate, increased blood pressure, increased physical strength, and increased breathing rate when getting angry. This factor is also effective in the individuals' way of thinking. When people achieve emotional awareness, they use better thoughts and processes. The rehearsal of this subject within training can teach the person not to impulsively become inclined to aggressive behavior and to consciously make selections with a bit of deep thinking when s/he encounter the initiation of anger symptoms, such as spasm, high rate of heart beat, and other similar symptoms. It seems that the participants thought that they were equipped with sufficient emotional awareness in the pretest stage although they lacked enough emotional awareness. In fact, significant changes were not observed in the experimental group in terms of emotional awareness because of their weakness in emotional awareness. This misunderstanding was evidently stated in participants' interview after receiving emotion regulation training.

As Kalawski (2011) argued, the use of facial expressions, breathing pattern and body posture in emotion regulation can be implemented as an emotional regulation technique or method. However, this is not a complete and definitive solution towards the resolution of the problems arising from students' anger. Therefore, it is necessary to employ complementary methods and techniques in addition to this technique. In this way, deeper and more profound effects may be observed in participants. The research instruments that are exposed to bias and the selection of only male participants can be referred to as the research limitations.

\section{References}

Abikoff, H., \& Klein, R. G. (1992). Attention- deficit hyperactivity and conduct disorder: comorbidity and implications for treatment. Journal of Counseling and Clinical Psychology, 60, 881-892.

Aldao, A., Nolen-Hoeksema, S., \& Schweizer, S. (2010). Emotion-regulation strategies across psychopathology: a meta-analytic review. Clinical Psychology Review, 30, 217-237. http://dx.doi.org/10.1016/j.cpr.2009.11.004

Aricak, O. T., \& Ozbay, A. (2016). Investigation of the relationship between cyberbullying, cybervictimization, alexithymia and anger expression styles among adolescents. Computers in Human Behavior, 55, Part A, 278-285. doi: http://dx.doi.org/10.1016/j.chb.2015.09.015

Barbour, C., Eckhardt, C., Davison, J., \& Kassinova, H. (1998). The experience and expression of anger in martially violent and discordant, and nonviolent men. Behavior therapy, 29, 173-191

Blake, C. S., \& Hamrin, V. (2007). Current approaches to the assessment and management of anger and aggression in youth: a review. Journal of Child and Adolescent Psychiatric Nursing, 20(4), 209-221.

Bushman, B. J., \& Anderson, C. A. (2002). Violent video games and hostile expectations: A test of the General Aggression Model. Personality and Social Psychology Bulletin, 28, 1679-1686

Campano, J. P., \& Munakata, T. (2004). Anger and aggression among Filipino students. Adolescence 39, 757-764

Dennis, T. A., Cole, P. M., Wiggins, C. N., Cohen, L. H., \& Zalewski, M. (2009). The functional organization of preschool-age children's emotion expressions and actions in challenging situations. Emotion, 9, 520-530.

Eisenberg, N., Cumberland, A., Spinrad, L., Fabes, A.,Shepard, A., \& Reiser, M. (2001). The relations of 
regulation and emotionality to children's externalizing and internalizing problem behaviour. Child Development, 72(4), 1112-1134

Feindler, E. L., \& Engel, E. C. (2011). Assesment and intervention for adolescents with anger and aggression difficulties in school settings. Psychology in the Schools, 48(3), 243-253.

Fives, C. J., Kong, G., \& Fuller, J. R. (2011). Anger, aggression, and irrational beliefs in adolescents. Cognitive Therapy Research, 35, 199-208.

Gambetti, E., \& Giusberti, F. (2009). Trait anger and anger expression style in children's risky decisions. Aggressive Behavior, 35, 14-23.

Gavrilescu, M. (2015). Recognizing emotions from videos by studying facial expressions, body postures and hand gestures. Telecommunications Forum Telfor (TELFOR), 23rd, 720-723.

Gratz, K. L., \& Roemer, L. (2004). Multidiminsional Assessment of Emotion Regulation and Dysregulation: Development, Factor Structure and Initial Validation of Thedifficultics in Emotion Regulation Scale. Journal of Psychopathology and Behavioral Assessment, 26(1), 41- 54

Kalawski, J. P. (2011). Using Alba EmotingTM to work with emotions in psychotherapy. Clin. Psychol. Psychother.

Kassinove, H. K., \& Sukholdosky, D. G. (1995). Anger disorders:Basic science and practice issues. In H.Kassinove (Ed), Anger disorders:Definition, diagnosis, and treatment (pp.1-26). Washington DC: Taylor \& Francis

Kurniawan, I. N., \& Dewi, W. A. K. (2016). Emotional Awareness and School Connectedness: A Prelimenary Study Among Students in Indonesia. Procedia - Social and Behavioral Sciences, 217, 622-625. http://dx.doi.org/10.1016/j.sbspro.2016.02.072

Lafrance, R. A., Kosmerly, S., Mansfield-Green, S., \& Lafrance, G. (2014). Disordered eating behaviours in an undergraduate sample: associations among gender, body mass index, and difficulties in emotion regulation. Canadian Journal of Behavioural Science/Revue Canadienne des Sciences du Comportement, 46, 320-326. http://dx.doi.org/10.1037/a0031123.

McCarthy, M. A., Barnes, A. F., \& Alpert, J. (1998). Childhood anger:So common, yet so misunderstood. Journal of Child and Adolescent Psychiatric Nursing,11(2), 69-78.

Neighbors, C., Vietor, A. N. \& Knee, C. R. (2002). A Motivational Model of Driving Anger and Aggression. Personality and Social Psychology Buletin, 28(3), 324-335.

Sandler, I. N., Tein, J. Y., West, S. G. (1994). Coping, stress, and the psychological symptoms of children of divorce: a cross-sectional and longitudinal study. Child Dev., 65(6), 1744-63. [PubMed]

Spielberger, C. D. (1988). Manual for the State.Trait. Anger Expression Inventory. Odessa, FL: Psychological Assessment Resources.

Szasz, P. L., Szentagotai, A., \& Hofmann, S. G. (2011). The effect of emotion regulation strategies on anger. Behaviour Research and Therapy, 49(2), 114-119. http://dx.doi.org/10.1016/j.brat.2010.11.011

\section{Copyrights}

Copyright for this article is retained by the author(s), with first publication rights granted to the journal.

This is an open-access article distributed under the terms and conditions of the Creative Commons Attribution license (http://creativecommons.org/licenses/by/4.0/). 